\title{
LABOUR EFFICIENCY IN CONSTRUCTION INDUSTRY IN EUROPE BASED ON FRONTIER METHODS: DATA ENVELOPMENT ANALYSIS AND STOCHASTIC FRONTIER ANALYSIS
}

\author{
Joanicjusz NAZARKO, Ewa CHODAKOWSKA \\ Bialystok University of Technology, ul. Wiejska 45A, 15-351 Bialystok, Poland
}

Received 19 Sep 2016; accepted 06 Feb 2017

\begin{abstract}
The primary problems pertaining to productivity or - more precisely - efficiency are: how to define it and how to measure it. This article studies technical efficiency in Stochastic Frontier Analysis (SFA) - the input-oriented frontier model - in the construction industry and compares it with Data Envelopment Analysis (DEA) results. The models explored in this paper were constructed on the basis of two outputs and personnel cost as an input. The research sample consisted of European countries. The aim was to determine whether there are substantial differences in estimation of efficiency derived from those two alternative frontier approaches. The comparison of results according to the models may translate into higher reliability of the undertaken labour efficiency analysis in construction and its conclusions. Although the results are not characterized by high compatibility, the conducted analysis indicated the most attractive countries taking into account labour cost to profit and turnover ratios of enterprises. One of the determinants which should not be ignored when analysing the labour efficiency is the level of development of a country; however, it is not the sole factor affecting the efficiency of the sector.
\end{abstract}

Keywords: Data Envelopment Analysis (DEA), Stochastic Frontier Analysis (SFA), Tobit regression, labour efficiency, construction industry.

\section{Introduction}

Efficient use of existing resources is an obvious determinant of economic development. The level of efficiency defines the level of prosperity which can be reached by an economy as well as the competitiveness of the country (The Global Competitiveness Report 2014-2015 2016). The pressure on the growth of efficiency and the introduction of more efficient production methods resulting in innovative or improved products and services relates to all sectors of the economy.

Construction belongs to ten activities that contribute the most to the Gross Value Added (GVA) in countries around the world, for example 5.7\% in Europe in 2013 (Eurostat 2016) or 4.0\% in the USA (U.S. Bureau of Economic Analysis 2016). This sector is also one of the largest industrial employers. In Europe, the construction industry provides over 12 million jobs (Eurostat 2016), and in the USA - over 6 million jobs (U.S. Bureau of Labor Statistics 2016), which implies that about 5\% workers are employed in the construction sector.

Construction sector is also important because it impacts many other sectors of the economy. The construction value chain covers a wide range of economic activities, e.g. mining, manufacturing and distribution of construc- tion products, services, such as design, management and controlling, maintenance, and ultimately renovation and demolition, with the recycling (Eurostat 2016).

Considering the European Union (EU), although construction plays an important role in the economy of all countries, there are strong differences between the states. Taking into account the contribution of construction to the total GVA and the number of people employed in construction in relation to the population, Europe is divided into three clusters. There are countries with slightly above-average contribution to GVA but with the highest percentage of employment, countries with the high contribution to GVA and an average share of people employed, and countries with the average contribution and average employment (Nazarko, Chodakowska 2015).

Awareness of the role of efficiency and the attempts to implement strategies for the improvement of productivity are related to the measurement of efficiency which has received increasing attention recently. It is a generally accepted view that any assessment depends both on the selected criteria of analysis and on the models used. The research question posed in this paper is to what degree the selection of methods determines the efficiency assess- 
Table 1. DEA and SFA - the interest in the methods and the areas of application in numbers

\begin{tabular}{|c|c|c|c|c|c|c|}
\hline \multirow[b]{2}{*}{ Years } & \multicolumn{2}{|c|}{$\begin{array}{c}\text { DEA or Data } \\
\text { Envelopment Analysis }\end{array}$} & \multicolumn{2}{|c|}{$\begin{array}{l}\text { SFA or Stochastic } \\
\text { Frontier Analysis }\end{array}$} & \multicolumn{2}{|c|}{$\begin{array}{l}\text { (DEA or Data Envelopment Analysis) and } \\
\text { (SFA or Stochastic Frontier Analysis) }\end{array}$} \\
\hline & Topic & Title & Topic & Title & Topic & Title \\
\hline 1978/1977-2016 & 27375 & 8618 & 17908 & 748 & 537 & 56 \\
\hline 2000-2016 & 24761 & 7775 & 16443 & 639 & 493 & 50 \\
\hline 2015-2016 & 1677 & 504 & 961 & 50 & 59 & 4 \\
\hline $\begin{array}{l}\text { Research Areas: Engineering } \\
\text { 1978/1977-2016 }\end{array}$ & 6327 & 2145 & 631 & 58 & 136 & 15 \\
\hline
\end{tabular}

Source: On the basis on publication indexes in WoS from All Databases [05.04.2015]

ment and whether the differences obtained could radically change the ratings. The authors attempt to answer this question on the basis of empirical research. Data Envelopment Analysis (DEA) and Stochastic Frontier Analysis (SFA) are analytical methods that have become highly popular and are frequently applied in the evaluation of the relative efficiency of different enterprises, organisations, intuitions, countries, sectors and others, that go by the common name of decision-making units (DMUs).

The bibliographic analysis of publications in Web of Science (WoS) related to the methods reflects the continued high interest and popularity of applying DEA and SFA in many research areas (Table 1). Engineering, however, is not among the top research fields.

Data presented in Table 1 illustrate high interest in both methods; however, DEA is predominant in spite of the data inaccuracies. Research in DEA as an efficiency measurement tool for production units starts with Charnes et al. (1978). The SFA approach originates from two papers: Meeusen and van den Broeck (1977) and Aigner et al. (1977), although most publications have been recorded in databases in recent years. This indicates the timeliness of the problem of assessing the efficiency by frontier benchmarking methods (Halicka 2016).

Although DEA and SFA have been used in many areas of research, they have not been the most popular ones in the construction sector and seem to have been underappreciated so far.

The expression search in WoS: (DEA or Data Envelopment Analysis) and (SFA or Stochastic Frontier Analysis) and construction, returned only three positions in April 2016. However, only one of them (Makridou et al. 2016) mentioned SFA, actually focussing on DEA only, while assessing energy efficiency trends of five most energy consuming sectors across the EU countries (construction industry among them). The added value of this work is an attempt to identify the main factors relating to the sector or the country and influencing the efficiency by the regression analysis.

Generally, most of the works on the subject of the industry efficiency concentrated on the energy or environmental efficiency, usually in terms of $\mathrm{CO}_{2}$ emissions. Outside Europe, energy efficiency was the theme of interest of Chen et al. (2016). DEA and SFA were applied to assess the energy efficiency of the Chinese construc- tion industry. In this publication, the first traditional DEA model was used to determine the efficiency of the Chinese regional construction industry, and in the next stage, the SFA model was employed to eliminate the influences of the environmental factors and random errors. Using DEA and Malmquist index, Xue et al. (2015) analysed the change in the energy consumption efficiency in the construction industry available in provinces of China.

As for the construction sector, some works focused on examining the efficiency of companies in the industry. Horta et al. (2013) used DEA to explore trends in the construction industry of the world on the basis of the efficiency of construction companies. Park et al. (2015) used the enterprise results and DEA in the construction industry in China, Japan and Korea.

Studies that compare DEA and SFA results have been used extensively but in different areas of application. Hjalmarsson et al. (1996) undertook a comparison across models based on Colombian cement plants. Cummins and Zi (1998) applied the two techniques to study the efficiency of U.S. life insurers. Cullinane et al. (2006) studied the efficiency of the container port industry utilising DEA and SFA. Kittelsen et al. (2015) estimated the productivity of Finnish hospitals in comparison to other Nordic countries and in regards to operating cost and patient dischargers. Depending on the data, the choice of method may have a significant impact on the conclusions or, on the contrary, the obtained results may be relatively stable.

This article is a continuation and a development of the issues of assessing the labour efficiency in construction initiated by Nazarko and Chodakowska (2015). The purpose of this article is a comparative measurement of the performance of the construction sector, identifying technically efficient countries that could be benchmarked by the two methods, DEA and SFA, as well as checking, discussing the consistency of results, and examining the economic factors that influence the final scores. The goal is to determine whether there are substantial differences in estimation of efficiency derived from these two alternative frontier approaches. In the authors' opinion the integrated comparison of results according to models may translate into higher reliability of the undertaken labour efficiency analysis in construction and its conclusions. 
The article is organised as follows: first, the frameworks of DEA and SFA methodologies are illustrated and then, the result are presented and discussed.

\section{Methodology (theoretical framework)}

The idea of DEA and SFA methods came from the Farrell's (1959) concept of efficiency. He proposed a measure of efficiency by referencing unit's performance to the production frontier or cost frontier of fully efficient, best performing firms.

Both methods, DEA and SFA, can accommodate non-controllable, non-discretionary environmental factors which affect the efficiency but are not under the control or management. Both methods account for multiple inputs and allow evaluating the technical efficiency (the ability to use the minimum inputs for constant outputs) and allocative efficiency (the ability to use the inputs in optimal proportions taking into account the prices), and compare the change in the efficiency through time using the available panel data.

Since the production and cost frontier are not known in practice and must be estimated, DEA uses the piecewise linear convex isoquant while SFA employs the parametric function, such as the Cobb-Douglas function. The second main distinctions is that SFA accounts for noise in data. Figure 1 shows the differences in the case of an input-oriented frontier and output-oriented frontier.

The inefficiency of DMU may be estimated by referring its cost to the minimum cost or maximum output determined by the frontier. DEA treats the residuals as inefficiency and does not separate noise in the score. SFA takes into account the presence of statistically random noise and decomposes the error term into two components. As a result, DEA envelopes all units, so that all DMUs lie in or on the frontier, while in SFA, some units may be situated outside the frontier (C and D in Fig. 1). As a consequence, DEA evaluates units A, B, C and D as fully cost efficient. Assuming the SFA methodology, error terms are composed of a symmetric random component and one-side inefficiency component (Kumbhakar, Lovell 2000). The gap between the SFA frontier and unit $\mathrm{E}$, consists of the inefficiency and error in the measurement. Unit C, which lies outside the SFA frontier, has the residual noise larger than the inefficiency.

The basic input-oriented radial DEA model (CCR-I DEA) for evaluating the efficiency of $\mathrm{DMU}_{\mathrm{O}}$ may be written as (Cooper et al. 2007):

$$
\begin{gathered}
\min \theta ; \\
\sum_{i=1}^{I} \lambda_{i} x_{i m} \leq \theta x_{O m}, \quad m=1, \ldots, M ; \\
\sum_{i=1}^{I} \lambda_{i} y_{i n} \geq y_{O n}, \quad n=1, \ldots, N ; \\
\lambda_{i} \geq 0, \quad i=1, \ldots, I,
\end{gathered}
$$

where: $X_{i}=\left(x_{i 1}, x_{i 2}, x_{i 3}, \ldots, x_{i M}\right)-$ input vector; $Y_{i}=\left(y_{i 1}\right.$, $\left.y_{i 2}, y_{i 3}, \ldots, y_{i N}\right)$ - output vector; $\lambda_{i}$ - vector of weights, specifying the intensity of the use of reference objects' technologies in the optimal $i$-th DMU's technology; $n=$ $1,2, \ldots, N$-number of outputs; $m=1,2, \ldots, M$ - number of inputs; $i=1,2, \ldots, I$ - number of DMUs; $\theta$ - technical efficiency.

In general, the stochastic frontier model in input-oriented perspective may be specified as (Koop et al. 1997):

$$
c_{i}=f\left(Y_{i} ; \beta\right)+v_{i}+u_{i},
$$

where: $c_{i}$ - observed total cost; $f\left(Y_{i}, \beta\right)$ - cost frontier function, for example Cobb-Douglas or translog; $Y_{i}$ - output of the $i$-th unit; $\beta$ - vector of parameters; $v_{i}$ - statistical noise independently distributed with the mean 0 , homoscedastic, $\sim \mathrm{N}\left(0, \sigma^{2}\right) ; u_{i}$ - non negative technical inefficiency term, homoscedastic, having typically half normal or truncated normal distribution.
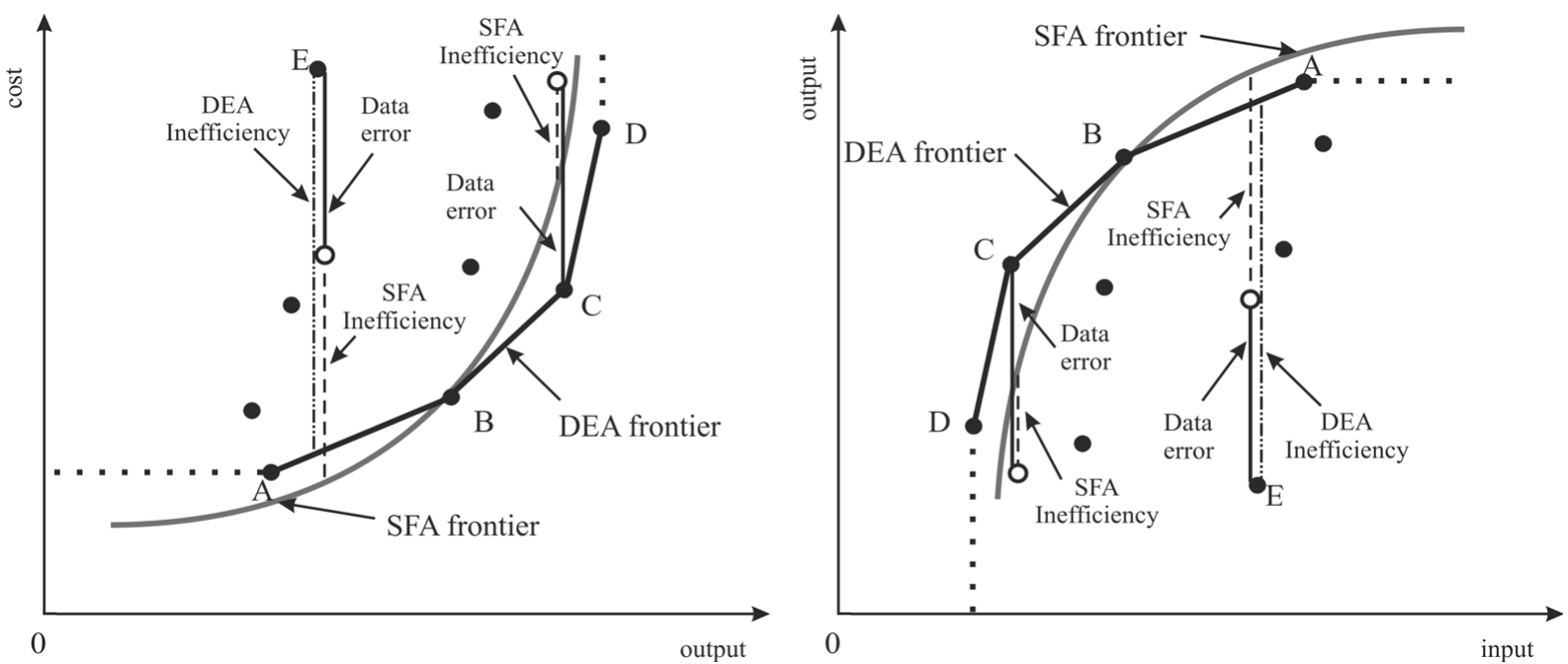

Fig. 1. DEA and SFA, compared to each other (author's elaboration on the basis Neumann et al. (2010)) 
And the technical efficiency is the ratio of observed cost to the minimum potential cost defined by the frontier. Assuming Cobb-Douglas form of the production function, the cost efficiency may be defined as (Coelli et al. 2005):

$$
E_{i}=\frac{\exp \left(\beta_{0}+\sum_{n=1}^{N} \beta_{n} \ln y_{i n}+v_{i}\right)}{\exp \left(\beta_{0}+\sum_{n=1}^{N} \beta_{n} \ln y_{\text {in }}+v_{i}+u_{i}\right)}=\exp \left(-u_{i}\right) .
$$

The parameters of the stochastic frontier may be estimated using the method of the maximum likelihood. An alternative approach may be the Bayesian estimation.

The final measure of efficiency (both $\theta$ and TE) takes the value between 0 and 1 in order to facilitate interpretation and comparison. However, the issue most often overlooked is the actual range of efficiency.

In input oriented model (1) inputs in virtual common technology are not greater than the smallest portion of the inputs of the $i$-th unit. The consequence is the final score not greater than 1. In the case of SFA, assuming the cost efficiency as the ratio of observed cost to the optimum cost, it theoretically ranges from 1 to infinity. The technical efficiency is bounded in the unit interval in production (output oriented) model. Analogous in the output orientation, the dual DEA models efficiency scores start from 1 and illustrate the inefficiency in utilizing inputs: a unit produces $\theta \geq 1$ times less outputs than it could, using its optimum technology. For the sake of uniformity, the inverse of scores is usually taken.

Both methods, as mentioned earlier, may account for the production environment. There is a variety of possible ways to adjust DEA and SFA to accommodate non-controllable factors, for example incorporate them directly into the models. The two-stage approach involves solving the DEA model or estimating the SFA model without environmental variables in the first step and then correcting the results by regressing technical inefficiencies on the environmental variables. In the case of SFA, this approach leads to the following model (Coelli et al. 2005):

$$
\begin{gathered}
u_{i}=g\left(\mathrm{Z}_{i} ; \gamma\right)+e_{i} \\
e_{i} \in N^{+}\left(0, \sigma_{e}^{2}\right),
\end{gathered}
$$

where: $Z_{i}-$ vector of environmental variables; $g\left(Z_{i} ; \gamma\right)-$ non-negative function; $\gamma$ - vector of parameters.

The summary of the comparison among DEA and SFA is given in Table 2.

DEA and SFA have drawbacks as well as advantages. Each method may be criticised and their results may be subject of polemics. Final efficiency scores always depend on the chosen methodology and should always be interpreted in the context of that methodology. Comparing the method results or even defining the range of the efficiency score may lead to more reliable final statements.

\section{Data for the efficiency calculation}

Industry efficiency may be measured as the average of technical efficiency of all companies in the industry (Coelli et al. 2005). Because it is impossible to identify all firms and collect data from all of them the authors decided to use aggregated indicators of performance. Based on Chodakowska et al. (2016), the two-stage models were applied with the following variables: personnel cost, gross operating surplus, turnover and Gross Domestic Product (GDP) per capita to explain the inefficiency (Fig. 2) from the last available non-provisional data table from the Annual Detailed Enterprise Statistics for Construction (Eurostat 2016). The study sample covered data on the construction sectors of 29 European countries in 2013. The choice of countries for the analysis was made on the basis of two criteria: the position in Europe and the

\begin{tabular}{|c|c|c|}
\hline & DEA & SFA \\
\hline $\begin{array}{l}\text { Parametric } \\
\text { and implications }\end{array}$ & $\begin{array}{l}\text { No } \\
\text { Functional form is not specified } \\
\text { Cannot test hypotheses, no goodness of } \\
\text { fit measures } \\
\text { Sensitive to outliers }\end{array}$ & $\begin{array}{l}\text { Yes } \\
\text { Functional form must be specified } \\
\text { Can test hypotheses concerning the coefficients, } \\
\text { goodness of fit measures } \\
\text { Deals with outliers }\end{array}$ \\
\hline Method of estimation & Uses mathematical programming & Uses maximum likelihood econometric estimation \\
\hline $\begin{array}{l}\text { Can be used to measure: } \\
\text { technical and allocative efficiency }\end{array}$ & Yes & Yes \\
\hline Account for noise & No & Yes \\
\hline Cross-sectional panel data & Yes & Yes \\
\hline $\begin{array}{l}\text { Accommodate environmental } \\
\text { variables }\end{array}$ & Yes & Yes \\
\hline
\end{tabular}
availability of reliable data. The authors are aware that

Table 2. Summary comparison of properties of DEA and SFA

Source: On the basis of Coelli et al. (2005) 


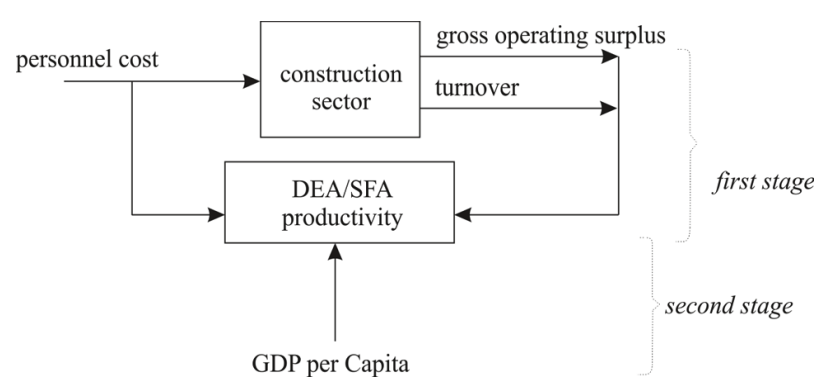

Fig. 2. Concept of the two-stage evaluation: DEA/SFA with regression

the choice of inputs and outputs, especially in the first stage, may be controversial and reflects only the financial health of the sector in different countries. It does not take into account the aspect of sustainable development (both in ecological and social terms) (Nazarko 2015). However, GDP/capita that was taken into account in the second stage allows correcting the obtained results by the economic situation and the degree of affluence.

Table 3 contains descriptive statistics of chosen variables. Figures 3 and 4 illustrate the data set for DEA and SFA.

The evaluated countries are very diverse in terms of the absolute values of the analysed variables. However, all considered variables have a high linear relationship: Pearson's correlation coefficient between the personnel costs and the turnover is 0.97 ; and between the personnel costs and the operating surplus is 0.71 . The following countries have the highest values of personnel costs and,

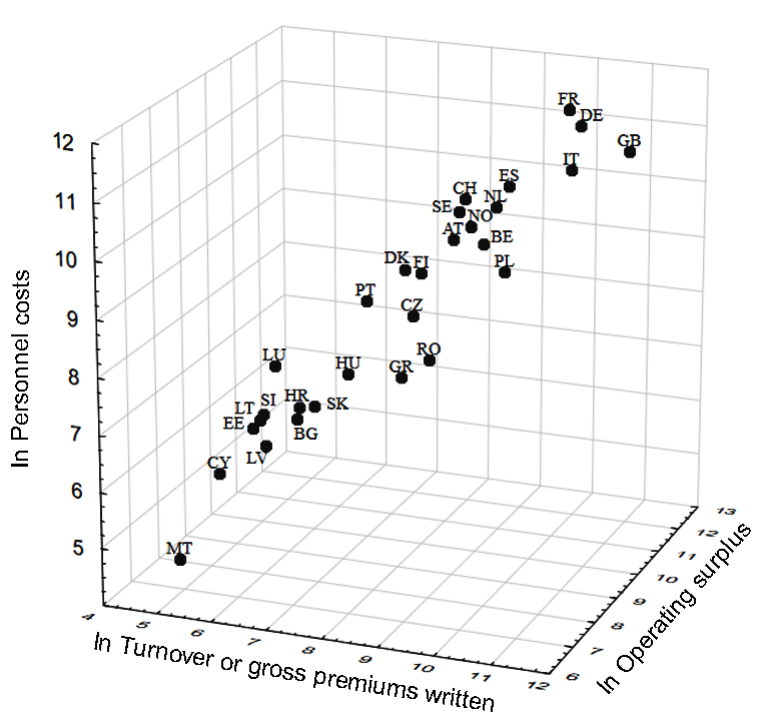

Fig. 4. Logarithmic variables for SFA (full names of countries are in Table 4)

at the same time, the biggest turnover: France, the United Kingdom, Germany and Italy (Fig. 4). On the opposite side are Malta, Cyprus, Latvia, Estonia, and Lithuania. The DEA method application in the case of the three variables allows drawing a frontier and the visual evaluation of the distance of each object from it, which reflects the efficiency (Fig. 3). The best country in terms of the turnover per unit of personnel costs is Bulgaria, with the highest ratio of gross operating surplus, and in terms of the personnel cost - Romania. The closest to the

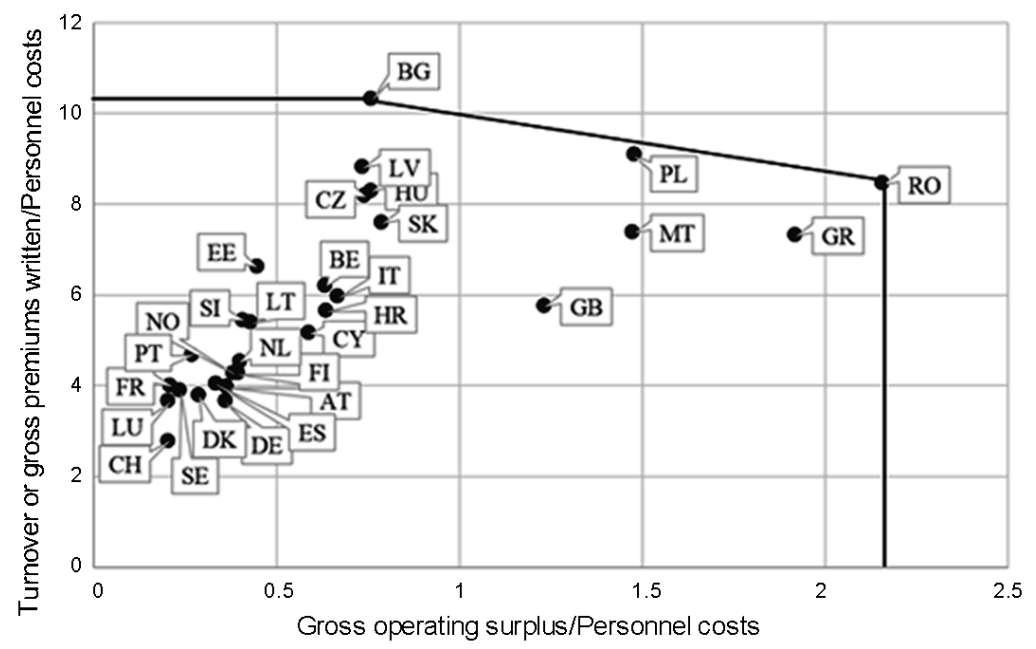

Fig. 3. Data set with DEA frontier (full names are in Table 4)

Table 3. Descriptive statistics of research sample

\begin{tabular}{lccccc}
\hline \multicolumn{1}{c}{ Variable } & Unit & Mean & Max & Min & Std. err. \\
\hline Personnel costs & Million euro & 12126.8 & 71433.8 & 108.8 & 17929.52 \\
Gross operating surplus & Million euro & 6015.1 & 50469.1 & 160.9 & 10239.65 \\
Turnover or gross premiums written & Million euro & 55083.7 & 284341.7 & 801.3 & 75918.47 \\
Gross domestic product per capita & Euro per capita & 28048.3 & 85300.0 & 5800.0 & 20349.23 \\
\hline
\end{tabular}


Table 4. Rating based on DEA and SFA results and on GDP per capita, Euro per capita at market prices

\begin{tabular}{|c|c|c|c|c|}
\hline Country & Code & SFA & DEA & GDP \\
\hline Austria & AT & 25 & 23 & 7 \\
\hline Belgium & $\mathrm{BE}$ & 9 & 12 & 9 \\
\hline Bulgaria & BG & 1 & 1 & 29 \\
\hline Switzerland & $\mathrm{CH}$ & 29 & 29 & 3 \\
\hline Cyprus & $\mathrm{CY}$ & 28 & 17 & 15 \\
\hline Czech Republic & $\mathrm{CZ}$ & 2 & 8 & 20 \\
\hline Germany & $\mathrm{DE}$ & 23 & 27 & 10 \\
\hline Denmark & DK & 24 & 26 & 4 \\
\hline Estonia & $\mathrm{EE}$ & 6 & 11 & 21 \\
\hline Spain & ES & 18 & 22 & 14 \\
\hline Finland & FI & 22 & 20 & 8 \\
\hline France & FR & 10 & 24 & 11 \\
\hline United Kingdom & GB & 17 & 10 & 12 \\
\hline Greece & GR & 21 & 4 & 18 \\
\hline Croatia & HR & 19 & 14 & 25 \\
\hline Hungary & HU & 4 & 7 & 26 \\
\hline Italy & IT & 8 & 13 & 13 \\
\hline Lithuania & LT & 15 & 16 & 23 \\
\hline Luxembourg & LU & 27 & 28 & 1 \\
\hline Latvia & LV & 3 & 5 & 24 \\
\hline Malta & MT & 26 & 6 & 16 \\
\hline Netherlands & NL & 14 & 19 & 6 \\
\hline Norway & NO & 20 & 21 & 2 \\
\hline Poland & PL & 5 & 3 & 27 \\
\hline Portugal & PT & 11 & 18 & 19 \\
\hline Romania & RO & 12 & 1 & 28 \\
\hline Sweden & $\mathrm{SE}$ & 16 & 25 & 5 \\
\hline Slovenia & SI & 13 & 15 & 17 \\
\hline Slovakia & SK & 7 & 9 & 22 \\
\hline
\end{tabular}

frontier from the beginning of the coordinate (DEA measures the radial efficiency) are Poland, Greece, Latvia, Malta, Hungary, and the Czech Republic.
Table 5. Descriptive statistics of DEA and the SFA score

\begin{tabular}{lccc}
\hline & DEA & SFA & SFA $^{-1}$ \\
\hline Min & $27.00 \%$ & $104.60 \%$ & $39.69 \%$ \\
Max & $100.00 \%$ & $251.97 \%$ & $95.60 \%$ \\
Median & $52.90 \%$ & $128.24 \%$ & $77.98 \%$ \\
Mean & $59.62 \%$ & $142.14 \%$ & $74.13 \%$ \\
Std. err. & $22.18 \%$ & $36.61 \%$ & $15.60 \%$ \\
\hline
\end{tabular}

\section{Analysis and results}

The DEA CCR-I and SFA basic cost model results are presented in Table 4, in the form of a ranking. Table 5 provides the summary of descriptive statistics of the efficiency score. Table 6 shows the SFA frontier model parameters and statistic.

The DEA efficiency ranges from 0.27 to 1 , with the average efficiency of 0.59 and a similar median, while the efficiency of SFA is from 1.04 to 2.52 with the average of 1.42 and a smaller median of 1.28.

Commenting on the SFA results, it should be said that the value of gamma means is nearly 0.937 of the variation in the composite error term is due to the inefficient component. Likelihood ratio (LR) is 2.755 . To compare the ranking from Table 4, Kendall Tau and Spearman correlations were estimated between scores together with GDP values (Table 7).

Table 7. Correlations coefficients

\begin{tabular}{|c|c|c|c|c|}
\hline & \multicolumn{2}{|c|}{ Spearman } & \multicolumn{2}{|c|}{ Kendall Tau } \\
\hline & $\begin{array}{c}\text { DEA } \\
\text { scores }\end{array}$ & SFA scores & $\begin{array}{c}\text { DEA } \\
\text { scores }\end{array}$ & $\begin{array}{c}\text { SFA } \\
\text { scores }\end{array}$ \\
\hline SFA scores & 0.627417 & & 0.495685 & \\
\hline $\begin{array}{l}\text { GDP per } \\
\text { capita }\end{array}$ & -0.817499 & -0.643174 & -0.638616 & -0.467247 \\
\hline
\end{tabular}

Note: Calculations done by using Statistica 12

Common-sense assumptions confirmed by the preliminary analysis and the values of correlation coefficients indicate that there is an inverse relationship between labour costs related to outputs and the GDP.

Table 6. SFA frontier model parameters and statistic

\begin{tabular}{cccc}
\hline & Coefficient & Standard error & (parameter estimate / standard error) \\
\hline$\beta_{0}$ & -3.1310032 & 0.3146598 & -9.9504387 \\
\hline$\beta_{1}$ & -0.4342708 & 0.1174886 & -3.6962797 \\
\hline$\beta_{2}$ & 1.5094598 & 0.1136723 & 13.2790470 \\
\hline $\begin{array}{c}\gamma=\sigma_{u}^{2} / \sigma^{2} \\
\sigma^{2}-\text { variance }\end{array}$ & 0.9367120 & & \\
\hline Log likelihood function & -1.5302045 & & \\
\hline
\end{tabular}

Note: Calculations done in Frontier v.4 by T. J. Coelli 
Table 8. Tobit regression results

\begin{tabular}{l|ccc|ccc}
\hline & \multicolumn{3}{|c}{ DEA } & \multicolumn{3}{c}{ SFA } \\
\cline { 2 - 7 } & $\begin{array}{l}\text { Estimated } \\
\text { coefficient }\end{array}$ & t-value & p-value & $\begin{array}{c}\text { Estimated } \\
\text { coefficient }\end{array}$ & t-value & p-value \\
\hline Intercept & 0.183593 & 2.0861 & 0.03697 & 0.647495 & 6.5096 & 0.00000 \\
GDP per capita & 0.000014 & 5.4918 & 0.00000 & -0.000010 & -3.4076 & 0.00066 \\
Pseudo R2 & 0.52885 & & & & 0.27947 & \\
Log likelihood & -4.52795580819 & & & & -8.06684766927 \\
\hline
\end{tabular}

Note: Calculations done in EasyReg by H. J. Bierens 2014.

The standard Tobit model was ran to check the background factor driving the inefficiency:

$$
y_{i}=\left\{\begin{array}{lll}
y_{i}^{*} & \text { if } & y_{i}^{*}>0 \\
0 & \text { if } & y_{i}^{*} \leq 0
\end{array},\right.
$$

where: $y_{i}^{*}=\beta x_{i}+\varepsilon_{i} ; \varepsilon_{i} \sim n\left(0, \sigma^{2}\right) ; x_{i}$ - GDP per capita; $y_{i}^{*}-$ efficiency.

The statistics of models of the selected predictor of the inefficiency are given in Table 8.

Before deriving the conclusion from the Tobit model parameters, some comments must be introduced. The efficiency obtained by DEA is confident to the interval $(0,1]$. The SFA input-oriented efficiency in practice is bounded $(1, \infty)$. In the first case, the logarithmic transformation was done to create a new variable $\mathrm{Z}=-\ln (Y) \epsilon[0, \infty)$, and in the second case, the values were shifted: $Z=Y-\min (Z)$ $\epsilon[0, \infty)$. Logarithmic transformation changes the interpretation of the sign of the coefficient: the negative coefficient of an independent $X$ variable implies a positive effect on the original dependent variable $Y$.

In any case, GDP per capita is an important and statistically significant variable that explains the value of the cost efficiency in constructions. Being aware that farreaching conclusions and radical proposals are limited by small degrees of freedom because the sample size was only 29 countries and the parameter estimation results may be unreliable, same interpretation of efficiencies in the sector across the countries may be attempted.

\section{Conclusions and implications}

There are studies that use DEA or SFA separately to assess the efficiency in construction. However, DEA is far more popular. It may be difficult to choose between different frontier based methods to perform the efficiency measurement, especially when there is a lack of clear unequivocal evidence. SFA is the preferable method when there are significant random influences and the functional form of relationship may be established, while DEA is applicable under the contrary conditions, i.e. having no random influences and no confidence as to the functional form (Sarafidis 2002). Both methods have their strengths and weaknesses discussed in many research papers.

It is important to note that efficiency scores depend on the chosen methodology. Mean efficiency calculated with the use of SFA, excluding measurement errors and the statistical noise from residuals, is greater than DEA which treats residuals as an inefficiency (Sarafidis 2002). On the other hand, SFA may overestimate the random component and inflate the efficiency. The comparison of the results seems to be a reasonable approach and allows assuming that reliable actual efficiency has a value between the results of DEA and SFA.

In the context of the selected variables, SFA evaluation was somewhat gentler and found that differences in the achieved efficiency between countries were smaller. The discriminative ability of the DEA method proved to be much greater. Therefore, it was decided to compare the ordering of the countries. In a few cases the difference amounted to more than 10 places in the ranking. SFA understated Malta, Greece, Cyprus, Romania, and raised the rating for France.

According to the analysis, the five most optimal countries to invest with the lowest labour costs in relation to profits were: Bulgaria, Czech Republic, Latvia, Hungary, and Poland (determined by SFA) or Bulgaria, Romania, Poland, Greece, and Latvia (determined by SFA). One may notice that these are the new countries of the EU that continue to be very attractive in terms of labour costs. Moreover, the conducted study found that there is a negative relationship between the wealth of a country (measured by GDP per capita) and the productivity of its construction sector.

The obtained results are far from obvious. They indicate that high labour costs in the old EU countries do not translate, at least proportionately, into higher efficiency of the construction sectors in those countries in relation to the new EU member states. The carried out analysis concluded that the aforementioned disproportion was not balanced out - as it could have been expected - by better technical endowment of the labour force in the old EU member countries. The performed calculations point at a high competitive potential of the construction industry in the new EU states. It is however beyond the scope of this paper to expose the economic, political, social etc. roots of that situation.

The classification into groups of countries - efficient, average and inefficient - is an alternative but also an extension to a simple comparison obtained by DEA and SFA specific positions in rankings of the countries according to the efficiency of labour costs. Simple 
agglomeration cluster analysis performed on the basis of two method scores gives the following results: Bulgaria as an unequalled benchmark, and Latvia, Poland, the Czech Republic, and Hungary as countries that are positively outstanding. The third group consists of the rest of analysed countries but there is a possibility to divide it into clusters: Slovakia, Estonia, Belgium, and Italy (cluster 1), Romania (cluster 2), Italy and Greece (cluster 3), and the rest (cluster 4). K means that clustering combines the best country and outstanding countries into one cluster: Bulgaria, Latvia, Poland, the Czech Republic, and Hungary. The second group has Slovakia, Romania, Estonia, Belgium, Italy, Greece, Malta, France, Portugal, the United Kingdom, and Slovenia. And the third has the remaining countries, i.e. Lithuania, Croatia, Netherlands, Sweden, Norway, Cyprus, Spain, Finland, Austria, Denmark, Germany, Luxembourg, and Switzerland.

The aim of this study was also to contribute to the existing literature on the efficiency. The variables selected covered the specific aspects of labour productivity and the results showed the complementarities of these two approaches. The authors believe that the presented analysis of the comparative efficiency in the construction industry provides a useful insight, however, is not exhaustive. Further research could involve various alternatives to selected criteria and the functional form, and the comparison of efficiency scores obtained over time using the panel data. Worth considering are the issues of working conditions, in particular occupational health and safety (Ejdys, Lulewicz-Sas 2010). The other proposition could be the application of the mixed methodology, i.e. Stochastic Data Envelopment Analysis (SDEA), instead of the comparison of the two. SDEA allows incorporating stochastic influences on the DEA frontier. This approach requires some probability assumption to utilize it in empirical studies (Sarafidis 2002).

\section{References}

Aigner, D.; Lovell, C. A.; Schmidt, P. 1997. Formulation and estimation of stochastic frontier production function models, Journal of Econometrics 6: 21-37. https://doi.org/10.1016/0304-4076(77)90052-5

Charnes, A.; Cooper, W. W.; Rhodes, E. 1978. Measuring the efficiency of decision making units, European Journal of Operational Research 2(6): 429-444. https://doi.org/10.1016/0377-2217(78)90138-8

Chen, Y.; Liu, B.; Shen, Y.; Wang, X. 2016. The energy efficiency of China's regional construction industry based on the three-stage DEA model and the DEA-DA model, KSCE Journal of Civil Engineering 20(1): 34-47. https://doi.org/10.1007/s12205-015-0553-3

Chodakowska, E.; Nazarko, J.; Šaparauskas, J. 2016. Environmental DEA technology for assessing the European countries. In print.

Coelli, T. J.; Rao, D. S. P.; O’Donnell, C. J.; Battese, G. E. 2005. An introduction to efficiency and productivity analysis. $2^{\text {nd }}$ ed. Springer.

Cooper, W. W.; Seiford, L. M.; Tone, K. 2007. Data envelopment analysis. A comprehensive text with models, applications, references and DEA-solver software. $2^{\text {nd }}$ ed. Springer.
Cullinane, K.; Wang, T.-F.; Song, D.-W.; Ji, P. 2006. The technical efficiency of container ports: Comparing data envelopment analysis and stochastic frontier analysis, Transportation Research, Part A 40: 354-374.

https://doi.org/10.1016/j.tra.2005.07.003

Cummins, J. D.; Zi, H. 1998. Comparison of frontier efficiency methods: an application to the U.S. life insurance industry, Journal of Productivity Analysis 10: 131-152. https://doi.org/10.1080/10803548.2010.11076859

Ejdys, J.; Lulewicz-Sas, A. 2010. An OH\&S management system as a source of information, International Journal of Occupational Safety and Ergonomics 16(4): 445-454. https://doi.org/10.1080/10803548.2010.11076859

Eurostat [online], 2016 [cited 25 May 2016]. Available from Internet: http://ec.europa.eu/eurostat

Farrell, M. J. 1957. The measurement of productive efficiency, Journal of Royal Statistical Society 120(3): 253-281. https://doi.org/10.2307/2343100

Halicka, K. 2016. Innovative classification of methods of the future-oriented technology analysis, Technological and Economic Development of Economy 22(4): 574-597. https://doi.org/10.3846/20294913.2016.1197164

Hjalmarsson, L.; Kumbhakar, S. C.; Heshmati, A. 1996. DEA, DFA and SFA: a comparison, Journal of Productivity Analysis 7(2-3): 303-327. https://doi.org/10.1007/BF00157046

Horta, I. M.; Camanho, A. S.; Johnes, J.; Johnes, G. 2013. Performance trends in the construction industry worldwide: an overview of the turn of the century, Journal of Productivity Analysis 39: 89-99. https://doi.org/10.1007/s11123-012-0276-0

Kittelsen, S. A. C.; Winsnes, B. A.; Anthun, K. S.; Goude, F.; Hope, Ø.; Häkkinen, U.; Kalseth, B.; Kilsmark, J.; Medin, E.; Rehnberg, C.; Rätto, H. 2015. Decomposing the productivity differences between hospitals in the Nordic countries, Journal of Productivity Analysis 43: 281-293. https://doi.org/10.1007/s11123-015-0437-z

Koop, G.; Osiewalski, J.; Steel, M. F. J. 1997. Bayesian efficiency analysis through individual effects: hospital cost frontiers, Journal of Econometrics 76: 77-115. https://doi.org/10.1016/0304-4076(95)01783-6

Kumbhakar, S. C.; Lovell, K. C. A. 2000. Stochastic frontier analysis. Cambridge University Press https://doi.org/10.1017/CBO9781139174411

Makridou, G.; Andriosopoulos, K.; Doumpos, M.; Zopounidis, C. 2016. Measuring the efficiency of energy-intensive industries across European countries, Energy Policy 88: 573-583. https://doi.org/10.1016/j.enpol.2015.06.042

Meeusen, W.; van den Broeck, J. 1977. Efficiency estimation from Cobb-Douglas production functions with composed error, International Economic Review 18(2): 435-444. https://doi.org/10.2307/2525757

Nazarko, L. 2015. Technology assessment in construction sector as a strategy towards sustainability, Procedia Engineering 122: 290-295. https://doi.org/10.1016/j.proeng.2015.10.038

Nazarko, J.; Chodakowska, E. 2015. Measuring productivity of construction industry in Europe with Data Envelopment Analysis, Procedia Engineering 122: 204- 212. https://doi.org/10.1016/j.proeng.2015.10.026

Neumann, K.; Verburg, P. H.; Stehfest, E.; Müller, C. 2010. The yield gap of global grain production: a spatial analysis, Agricultural Systems 103: 316-326. https://doi.org/10.1016/j.agsy.2010.02.004

Park, J. L.; Yoo, S. K.; Lee, J. S.; Kim, J. H.; Kim, J. J. 2015. Comparing the efficiency and productivity of construction firms in China, Japan, and Korea using DEA and DEA-based Malmquist, Journal of Asian Architecture and Building Engineering 14(1): 57-64. https://doi.org/10.3130/jaabe.14.57 
Sarafidis, V. 2002. An assessment of comparative efficiency measurement techniques [online], [cited 05 April 2016]. Available from Internet: http://www.europe-economics.com/download/eeeff.pdf

The Global Competitiveness Report 2014-2015 [online], [cited 25 May 2016]. Available from Internet: http://reports.weforum.org/global-competitiveness-report-2014-2015/
U.S. Bureau of Economic Analysis [online], [cited 25 May 2016]. Available from Internet: https://www.bea.gov/

U.S. Bureau of Labor Statistics [online], [cited 25 May 2016]. Available from Internet: https://www.bls.gov/

Xue, X.; Wu, H.; Zhang, X.; Dai, J.; Su, C. 2015. Measuring energy consumption efficiency of the construction industry: the case of China, Journal of Cleaner Production 107: 509-515. https://doi.org/10.1016/j.jclepro.2014.04.082

Joanicjusz NAZARKO. PhD, DSc, is a professor of both technical and economic sciences, ordinary member of the Polish Academy of Engineering and a Presidium member of the Production Engineering Committee of the Polish Academy of Sciences. He is currently serving as the Director of International China and Central-Eastern Europe Institute of Logistics and Service Science. He also holds the posts of an Professeur Associé at the Université du Québec à Trois-Rivières (Canada) and an Honorary Professor of Zhejiang University Ningbo Institute of Technology (China). He was a Rector of Bialystok University of Technology in the years 2005-2008. His academic interests include technology foresight, forecasting, modelling and simulation in technical and economic systems, logistic systems as well productivity analysis and benchmarking. He is the author or co-author of more than 200 technical and scholarly works published in reputable journals. He regularly speaks and presents his work at numerous Polish and international conferences. He has been a visiting professor at universities in China, Finland, Great Britain, Canada, Germany, Lithuania and USA.

Ewa CHODAKOWSKA. PhD - received her PhD degree in management sciences from the Faculty of Management at the Warsaw University. Member of the IEEE Systems, Man, and Cybernetics Society, Section of Classification and Data Analysis of the Polish Statistical Association and the Polish Society of Production Management. Area of research interests: productivity, data analysis, forecasting and data science. 